\title{
¿QUÉ QUEREMOS DECIR CUANDO DECIMOS QUE LAS SERIES DE TELEVISIÓN SON "FILOSÓFICAS”?
}

\author{
WHAT DO WE MEAN WHEN WE SAY THAT TELEVISION SERIES \\ ARE "PHILOSOPHICAL"?
}

Laura García Díaz

DOI: 10.26754 /ojs_arif/arif.202115350

\begin{abstract}
RESUMEN
En este trabajo propongo analizar las series de televisión como un producto que, mediante sus tramas, es capaz de transmitir contenido filosófico. Para ello, comenzaré estableciendo una justificación teórica de las series como producto artístico y, veremos a través de Noël Carroll (Carroll 2011) un análisis de las imágenes en movimiento como vehículo filosófico. Tras ello, mostraré las similitudes que presentan las series con los relatos literarios y propondré la forma en que entiendo su potencial filosófico. En definitiva, pretendo analizarlas como relatos especialmente interesantes para la filosofía por incentivar la reflexión en los espectadores y ampliar el punto de vista desde el cual enfocan la realidad.
\end{abstract}

PALABRAS CLAVE: series de televisión, perspectivismo, literatura, conocimiento, cultura

\section{ABSTRACT}

In this work, I propose to analyze television series as a product that, through its plots, are able of transmitting philosophical content. To do this, I will begin by establishing

\footnotetext{
1 Trabajo financiado por la Agencia Canaria de Investigación, Innovación y Sociedad de la Información de la Consejería de Economía, Conocimiento y Empleo, por el Fondo Social Europeo (FSE) Programa Operativo Integrado de Canarias 2014-2020, Eje 3 Tema Prioritario $74(85 \%)$ y por el proyecto de investigación "Personal Perspectives": Concepts and Applications, FFI2018-098254-B100, Ministerio de Economía y Competitividad, Gobierno de España. ${ }^{2}$ Universidad de La Laguna. Investigadora predoctoral. Líneas de investigación: Filosofía de la ciencia, Estudios sociales de la ciencia, Filosofía y cultura popular. E-mail: lgarciad@ull.edu.es
}

Recibido: 03/05/2021. Aceptado: 08/07/2021

Análisis. Revista de investigación filosófica, vol. 8, n. ${ }^{\circ} 1$ (2021): 73-94

ISSNe: 2386-8066

Copyright: Este es un artículo de acceso abierto distribuido bajo una licencia de uso y distribución "Creative Commons Reconocimiento No-Comercial Sin-Obra-Derivada 4.0 Internacional" (CC BY NC ND 4.0) 
a justification for the series as an artistic product and, through Noël Carroll (Carroll 2011), we will see an analysis of moving images. After that, I will show the similarities that the series have with literary stories and I will propose the way in which I understand their philosophical potential. In short, I intend to analyze them as stories that are especially interesting for philosophy because it encourages reflection in viewers and broadens the point of view from which viewers focus on reality.

KEYWORDS: TV series, perspectivism, literature, knowledge, culture

\section{INTRODUCCIÓN}

Las series de televisión son cada vez más utilizadas para ejemplificar problemas o conceptos filosóficos. Desde hace ya algún tiempo pueden encontrarse series cuya visualización sobrepasa el mero entretenimiento. En sus tramas encontramos temas que nos preocupan y nos apasionan, como puede ser la identidad, la libertad, el desarrollo de la ciencia y la tecnología, e incluso los problemas medioambientales a los que se enfrenta el planeta Tierra. Todos estos temas han sido estudiados por la filosofía y tratados en la literatura, y han tenido también repercusión en las manifestaciones artísticas. El cine, considerado desde hace ya más de un siglo como el séptimo arte, suele reflejar en sus obras este tipo de reflexiones. Por su parte, las series de televisión, a pesar de lograr un contenido reflexivo e incluso ser capaces de conseguir en ocasiones un carácter divulgador, suelen aparecer denostadas por pertenecer a la industria del entretenimiento o, lo que es lo mismo, a la industria cultural. Que sean producidas para alcanzar un gran número de espectadores y obtener el mayor número de beneficios posibles, ha hecho que pierdan credibilidad y estatus artístico.

Lo que me propongo en este trabajo es analizar las series de televisión como un producto que, aun procediendo de la industria cultural, puede adquirir valor artístico y conformarse como un medio de divulgación filosófica. Para desarrollar esta idea, comenzaré por realizar un acercamiento a la forma en que se ha entendido la cultura de masas, para intentar mostrar que puede ser entendida como arte genuino. Esto me permitirá establecer una justificación teórica de las series como un producto cultural. A continuación, pasaremos a la cuestión de si podemos considerar que en los productos audiovisuales, concretamente en las series de televisión, se haga filosofía. A través de Noël Carroll veremos un análisis de estas cuestiones que nos permitirá ver en qué sentido considera que puede decirse que una serie de televisión pueda transmitir o generar contenido filosófico. Tras esto, 
podremos pasar a realizar una caracterización de las series de televisión como un producto que permite plasmar puntos de vista filosóficos que posibilitan que el espectador adquiera un conocimiento que sobrepasa el que adquiere de forma directa a través de su experiencia. En definitiva, a través de este recorrido mostraré que las series de televisión son un producto procedente de la cultura de masas que adquiere estatus artístico y que, además, resulta especialmente eficaz para la divulgación filosófica.

\section{EL VALOR ARTÍSTICO DE LA CULTURA DE MASAS}

Si nos preguntamos sobre qué caracteriza la cultura de masas, parece imprescindible fijarnos en el momento en que surge dicho término. El concepto fue desarrollado por Theodor Adorno y Max Horkheimer para hacer referencia a la creación de un tipo de productos culturales que comenzaban a aparecer en la década de los 40. Se trataba de un momento en el que se ponía de manifiesto la necesidad de pensar sobre ese nuevo fenómeno que se denominó cultura de masas, así como en las repercusiones que esta podría tener en el proceso de creación artística, en la constitución de los individuos o, incluso, en el desarrollo de las sociedades. La escuela de Frankfurt entendió que la cultura de masas, especialmente el cine, podría llegar a tener un desarrollo deseable que dependería del grado de realidad social que pudiesen expresar. Sin embargo, creían que el desarrollo de la cultura de masas que estaba surgiendo en ese momento no era más que una forma de entretener a los espectadores y hacerles evadirse del cansancio de la jornada laboral. A su parecer, la cultura de masas no es arte genuino por no cumplir con las expectativas de emancipación que entendían que debía caracterizar al arte.

Así podemos resumir la polémica postura que mantenían algunos de los más importantes críticos culturales, tanto los críticos conservadores como los progresistas: la cultura estaba siendo transformada para poder ser poseída por las masas. Esta alternativa pareció más factible que la utópica idea de elevar a las masas para que fuesen capaces de acceder a lo que, en oposición, ha sido tradicionalmente entendida como cultura de élites: "la cultura era por definición resistente frente a las dinámicas sociales, pero la cultura de masas es indefectiblemente complaciente y legitimante." (Rodríguez 2012: 17). Los argumentos contra la cultura de masas hacían referencia a la pérdida del refinamiento y la sensibilidad del gusto que produciría el sometimiento del arte al sufragio universal. A lo largo del tiempo, los estudios sobre la cultura han seguido desarrollándose en torno a esta clasificación entre cultura de masas y cultura de élites, a pesar de que ambas hayan pasado a 
ser entendidas como producto; los gustos estéticos son clasificados y catalogados para que cualquiera pueda acceder a la parcela cultural que más le interese. Por este motivo, en Dialéctica de la Ilustración, Adorno y Horkheimer deciden denominar a este fenómeno como "industria cultural", pues entienden que no se trata de una cultura que surge de forma espontánea de las masas, sino que es una manifestación de cómo el cambio de las condiciones de producción llega también al sector artístico y cultural: "la técnica de la industria cultural ha llevado sólo a la estandarización y producción en serie y ha sacrificado aquello por lo cual la lógica de la obra se diferenciaba de la lógica del sistema social" (Adorno y Horkheimer 2005: 166). El cine, la radio, la televisión y el resto de la cultura de masas no solo vivieron una apropiación por parte de la industria, sino que también la administración gubernamental estuvo interesada en las posibilidades de estos medios como una forma de influir sobre los ciudadanos. La televisión fue vista por estos filósofos como una técnica especialmente capaz de acercar la cultura a los consumidores, sin embargo, se trata de una cultura rebajada o diluida, un ingrediente perfecto para conseguir que las masas sigan siéndolo; les permiten descansar y distraerse mientras que se aleja cualquier posibilidad de reflexión acerca de sus condicionamientos.

En general, los más importantes críticos culturales, tanto los conservadores como los progresistas, han defendido que la cultura estaba siendo transformada para poder ser poseída por las masas. Dwight Macdonald, periodista y crítico cinematográfico, también se posicionó en esta línea. Desde su perspectiva (Macdonald 1963) la cultura de masas solo es producida para el consumo de un público de masas y la distingue de la cultura popular porque considera que esta puede ser considerada arte elevado:

"A veces se le llama "Cultura popular", pero creo que "Cultura de masas" es un término más acertado, ya que su rasgo distintivo es que es única y directamente un artículo de consumo masivo, como el chicle. Una obra de alta cultura es ocasionalmente popular, después de todo, aunque esto es cada vez más raro. Este Dickens fue incluso más popular que su contemporáneo, G. A. Henty, con la diferencia de que era un artista que comunicaba su visión individual a otros individuos, mientras que Henty era un fabricante impersonal de una mercancía impersonal de las masas." (Macdonald 1963: p. 59)

Macdonald señala que el cine y la televisión son tecnologías adaptadas a la fabricación y distribución masiva, y que esta razón las aleja de lo que hasta entonces se conocía como arte o cultura. Él define la cultura de masas como un crecimiento parasitario de la alta cultura. Entiende que la irrupción de las masas 
en el escenario político ha significado en el arte una ruptura de la distinción entre el folk art y la alta cultura. Desde su perspectiva, el arte de masas es un reflejo de la alta cultura, a la que no le quedará mas remedio que competir con el arte de masas o fusionarse con ella:

"El arte popular creció desde abajo. Fue una expresión espontánea y autóctona de la gente, formada por ellos mismos, prácticamente sin el beneficio de la alta cultura, para satisfacer sus propias necesidades. La cultura de masas se impone desde arriba. Está fabricada por técnicos contratados por empresas; sus audiencias son consumidores pasivos, su participación se limita a la elección entre comprar y no comprar. Los señores del kitsch, en resumen, explotan las necesidades culturales de las masas para obtener ganancias y/o mantener su dominio de clase." (Macdonald 1963: 60)

MacDonald piensa que la gente se ve obligada a elegir entre ir al cine o un concierto, entre leer a Tolstoi o una novela policiaca, ver a grandes maestros musicales o un programa de televisión: "el patrón de sus vidas culturales está "abierto" hasta el punto de ser poroso. El buen arte compite con el kitsh, las ideas serias compiten con las fórmulas comercializadas" (Macdonald 1963: 61). Así es como introduce la Ley de Gresham en el arte: las cosas malas expulsan a las buenas debido a que son más fáciles de comprender y de disfrutar. En definitiva, lo más importante de su crítica al arte de masas es que considera que sus productos han sido creados para llegar al gran público y por tanto no hay en ellos una expresión distintiva, es impersonal.

A pesar de que la mayoría de voces acusen al arte de masas de no ser arte genuino, podemos encontrar otras opiniones. Noël Carroll, uno de los filósofos del arte contemporáneos más importantes, analiza la cultura de masas desde otra óptica y recoge la discusión sobre el arte de masas con la pretensión de mostrar que es un tema legítimo de la estética filosófica. Carroll (Carroll 2002) defiende la idea de que el arte de masas puede ser objeto de la estética filosófica. Se posiciona ante las diferentes críticas que ha soportado el arte de masas desde sus inicios, y también recoge las defensas. Es especialmente interesante cómo Carroll se contrapone a Macdonald, porque considera que no hay razón para suponer que lo común del gran público sea incompatible con la expresividad distintiva:

“Aunque 'original' o 'distintivo' son lógicamente contrarios a 'común', creación original no es incompatible con recepción común. La premisa parece avanzar retóricamente con el supuesto de que, dicho toscamente, lo que es común y lo que es distintivo no se mezclan. Pero esto apenas resulta persuasivo cuando nos damos cuenta de 
que, cuando se afirma de manera no elíptica, aquello de lo que estamos hablando es lo que resulta común a los receptores y lo que resulta distintivo de los emisores. No hay razón para suponer que una expresión distintiva no sea accesible al gran público en virtud de su entendimiento e intereses comunes. Que una expresión particular sea original o no tenga precedentes, no implica que sea inaccesible al entendimiento común del público de masas." (Carroll 2002: 37)

Carroll entiende que el arte de masas sí que sería arte en la medida en que resulta expresivo y no todas las obras el arte de masas contribuyen a rebajar el nivel de gusto, y da como ejemplo de esto las obras de cineastas como Charlie Chaplin, Buster Keaton o Alfred Hitchcock. Esta idea es importante no solo porque derriba la crítica de MacDonald al arte de masas, sino porque nos hace ver que aunque el arte de masas pretenda llegar a un gran número de personas, puede ser aún así expresivo y personal.

Así, podemos pensar que, aunque las series surgen de la industria y pretenden entretener al gran público, esto no las despoja necesariamente de la expresividad propia de los productos artísticos. Su contenido logra convertirse en un producto de excelencia artística en tanto que son capaces de reflejar la realidad social, tal y como esperaba Adorno del arte. Actúan como espejo que refleja las inquietudes de las sociedades que las crean. Pero también se pueden mostrar en ellas puntos de vista personales y expresivos. En este sentido, no puede decirse que en las series encontremos un empobrecimiento de la cultura, sino más bien todo lo contrario; muchas de ellas consiguen incentivar la reflexión acerca de nuestros condicionamientos o replantearnos el significado de las realidades que nos rodean. A continuación, veremos a través de Carroll un análisis que intenta dilucidar si puede considerarse que los productos audiovisuales (o, como él los llama, imágenes en movimiento) pueden ser filosóficos y en qué sentido lo son a su parecer.

\section{LAS IMÁGENES EN MOVIMIENTO COMO VEHÍCULO FILOSÓFICO}

En la obra de Carroll podemos encontrar una defensa del carácter artístico de la cultura de masas pero, además, realiza un análisis filosófico de los productos audiovisuales o, como los denomina, las imágenes en movimiento, término con el que se refiere tanto al cine, como a las series de televisión o incluso los videojuegos. Lo que se pregunta Carroll (Carroll 2011) es si pueden ser un vehículo filosófico, es decir, lo que le interesa es si las imágenes en movimiento pueden producir filosofía original, o si solo son capaces de ilustrar o narrar la filosofía que ya existe. Nos dice que el simple hecho de grabar a una persona exponiendo ideas filosóficas, 
no puede ser considerado un caso de creación filosófica porque aparece sólo de forma contingente, es decir, ahí no se da una filosofía articulada mediante la técnica cinematográfica. Entiende que para que las imágenes en movimiento puedan considerarse "películas filosóficas" deben desarrollar una idea original y no limitarse a ilustrar, contar o grabar una idea ya existente y "hacerlo de forma tal que el arte de la imagen en movimiento juegue algún papel en la articulación del asunto filosófico en cuestión" (Carroll 2011: 242). Carroll recoge una objeción que parece obvia si nos preguntamos cómo pueden las imágenes en movimiento hacer filosofía, y es que la filosofía es general, mientras que la imagen en movimiento se refiere por su naturaleza a casos particulares. Para explicar esto mejor, recurre a la película Secretos de un alma (1926) de G.W. Pabst, que pretendía ser un manual de psicoanálisis y que contó para ello con la ayuda del psicoanalista Hans Sachs. Si damos por válido el psicoanálisis como sistema filosófico, la película Secretos de un alma puede ser entendida como una obra que ilustra cinematográficamente ciertas tesis psicoanalistas. Lo que nos dice Carroll es que aunque las teorías ilustradas en una película sean generales o hayan sido pensadas como universales, si la película se basa en el estudio de un caso singular, nunca puede producir un conocimiento tan general como el de la filosofía:

"Es decir, el carácter particular de la imagen en movimiento impide que ésta pueda proporcionar las evidencias suficientes para sustentar afirmaciones supuestamente filosóficas y generales. El argumento escéptico aquí es que, debido a su crónica incapacidad para obtener la cantidad de evidencia que la justificación de una proposición general necesita, la imagen en movimiento no es un canal apropiado para transmitir un conocimiento general. Está en la naturaleza de la imagen en movimiento presentar un caso singular, y un caso no es suficiente para justificar el tipo de proposiciones generales que son la base de la filosofía." (Carroll 2011: 244)

A pesar de considerar que una imagen en movimiento puede transmitir creencias generales, entiende que debido al carácter particular de las películas, tanto en sus imágenes como en sus tramas, es improbable que puedan justificar una creencia general como lo hace la filosofía. Por eso podría decirse que las imágenes en movimiento no son una fuente sólida de conocimiento filosófico. Por otra parte, contempla casos en que una película pueda servir como contraejemplo a una afirmación filosófica, como dice que ocurre en la película Delitos y faltas (1989) de Woody Allen, donde se puede concluir que el crimen no merece la pena o que la inmortalidad nunca puede coexistir con la felicidad. Carroll considera que aunque podamos insistir en que las películas carecen de competencia filosófica debido a que se ocupan de casos individuales y no tienen recursos necesarios para 
justificar creencias de alcance general, como mínimo se puede ver en ellas una forma de dar contraejemplos. Sin embargo, entiende que esto puede ser válido sólo para ciertas películas basadas en narraciones de historias con personajes, pero que esta no es la única forma de tratar cinematográficamente tesis generales, dado que hay otras formas de hacer cine. Aquí es donde introduce una objeción más importante con respecto a la capacidad de las imágenes en movimiento para hacer filosofía, y es que entiende que, aunque encontremos películas donde se plasmen teorías filosóficas, se trata de hechos que no son reales a modo de documental, sino que son representaciones diseñadas. Esto es, las pruebas son construidas para defender la hipótesis general que plantea la película. Carroll nos dice que muchas de las películas llamadas filosóficas, son ficciones donde las evidencias que aparecen no son solo insuficientes, sino que están manipuladas o sesgadas. De esta forma, intenta responder al escéptico que niega que las imágenes en movimiento corroboren tesis filosóficas porque aportan menos pruebas de las necesarias para justificar proposiciones generales y porque "tales pruebas son ejemplos ad hoc diseñados de forma sesgada. Dicho brevemente: el modo en que las películas plantean evidencias es insuficiente." (Carroll 2011: 246)

Carroll entiende que el principal problema del tipo de películas que llamamos filosóficas es que las teorías que presentan son fundamentalmente empíricas, como ocurre en Secretos de un alma y Mecánica del cerebro (1926). Pero apunta que este problema no surgiría si su contenido filosófico fuera conceptual en lugar de empírico, y nos dice:

"Con esto no pretendo afirmar, de forma polémica, que toda verdadera filosofía es solo un problema de conceptos. Lo que pretendo decir es que bastaría con aceptar una cierta dimensión conceptual en la filosofía o, al menos, una dimensión no del todo empírica, para eludir los recelos escépticos respecto a su capacidad probatoria. Si una película utilizara los medios propios del cine para articular un argumento conceptual de manera original, no está claro que el tipo de rechazo del escéptico basado en la falta de evidencia como el que acabo de presentar tuviera algún alcance." (Carroll 2011: 246)

Para aclarar esta idea propone que nos fijemos en Serene Velocity (1970) una película de Ernie Gehr que Carroll encaja dentro del cine minimalista, una forma de meta-cine que, a su parecer, se engloba en dos categorías estilísticas: una que recuerda al minimalismo clásico porque su principal característica es mostrar formas geométricas, y otra que consiste en crear un sistema esquemático y fácilmente reconocible. Ambas características son analizadas por Carroll a través de esta película, Serene Velocity, donde encuentra tanto una forma como 
un sistema reconocible. La película, nos dice, ilustra sobre los principios de la animación e incita al espectador a reflexionar sobre la diferencia entre la fotografía y el cine: "la película se plantea como un experimento mental y filosófico que, en lugar de estar articulado mediante palabras, se construye mediante imágenes". (Carroll 2011: 252) Considera que esta película sugiere algo con respecto a la naturaleza de la forma de arte o medio al que pertenece, pues su tema principal es el movimiento frente a la quietud. Este le parece un ejemplo claro de lo que sería hacer filosofía mediante imágenes en movimiento. Encuentra en Serene Velocity una materialización del tipo de experimentos mentales que los filósofos de la imagen en movimiento exponen en sus trabajos y, además, presenta un caso individual construido expresamente para apoyar precisamente la tesis de que el movimiento es una característica esencial y definitoria de toda película.

Siguiendo con este análisis de las imágenes en movimiento como forma de hacer filosofía, Carroll señala que el tema de la esencia del cine no es la única pregunta que la filosofía puede plantear en este medio. Nos dice que el escéptico, si antes podía argüir que el problema de hacer filosofía a través del cine era la incapacidad del medio para proporcionar evidencias empíricas, ahora podrá decir que carece de argumentación, pues Serene Velocity es una película muda. Esto le parece, sin embargo, una objeción que reposa en un concepto de argumentación demasiado restrictivo y propone pensar en las películas como una especie de experimentos mentales. Los experimentos mentales han sido diseñados para alcanzar conclusiones filosóficas, animando a reflexionar a partir de unas circunstancias determinadas que nos derivan hacia una conclusión mediante un proceso reflexivo: "El experimento mental moviliza los recursos del oyente (sus creencias sobre el mundo y su marco conceptual) para que alcance un resultado. Como la pregunta retórica, el experimento mental es una manera de anticipar una conclusión y por lo tanto, si no somos excesivamente restrictivos, es válido como argumento filosófico" (Carroll 2011: p256). Carroll entiende que, de forma análoga, los artistas pueden investigar en el cine minimalista acerca del concepto de cine. Considera que el hecho de que los espectadores no estén familiarizados con este tipo de cine no hace que éste pierda su dimensión filosófica y que no debemos presuponer que el público no sea capaz de entender el tema que aborda Gehr en Serene Velocity.

Tras haber analizado en qué sentido cree que puede ser una película filosófica, pasa a la cuestión que más interesante resulta: si las interpretaciones de las películas pueden también ser filosóficas. A su parecer, la interpretación tendría que ser tanto una contribución al conocimiento filosófico como una interpretación legítima 
de la película en cuestión. Fijándose en el ejemplo de la película Atrapado en el tiempo (1993) de Harold Ramis, nos dice que puede que encontremos ahí el mito del eterno retorno de Nietzsche pero que no se trata de una película filosófica que cree filosofía original: "la localización interpretativa de la filosofía preexistente contenida en una película no es un ejercicio filosófico" (Carroll 2011: 260). Sin embargo, reconoce que es frecuente encontrar filósofos en la actualidad que afirman que existen películas que ilustran alguna filosofía. Entiende que preguntarnos acerca de si la interpretación de una obra de arte cinematográfica puede ser considerada como filosofía dependerá de lo que se entienda por filosofía. Carroll entiende por filosofía aquella que considera el análisis conceptual como una de sus partes importantes y, por tanto, le interesa el tipo de película que pueda contribuir al análisis conceptual. Señala que la interpretación de algunas obras de arte requieren que el intérprete realice un ejercicio filosófico. Dice que hay ideas filosóficas en la obra pero que, a menudo, son elípticas y requieren de que el intérprete las complete y considera que puede ser "análogo al del historiador de la filosofía que al reconstruir los razonamientos de un filósofo clásico los completa de una forma que va más allá de la letra del texto pero no de su espíritu." (Id. 261) Esto resulta especialmente importante, porque encuentra una relación entre la actividad que realizamos los filósofos al interpretar los textos y lo que hacen los espectadores al visualizar imágenes en movimiento. Siguiendo el ejemplo de Serene Velocity, Carroll nos dice que puede ocurrir que, al igual el historiador de la filosofía puede ampliar o ilustrar los argumentos de un pensador anterior para que conecte con las preocupaciones contemporáneas, el intérprete de cine puede tratar de perfilar el significado filosófico de la película para los debates actuales y que sobrepase de esta forma las intenciones de Gehr. En este momento de interpretación, que puede incluso sobrepasar lo que quiere decir el autor de la obra, encuentra Carroll un ejercicio filosófico:

"Cuando un historiador de filosofía amplía o explica el asunto que está tratando, o clarifica las implicaciones de un texto no explicitadas en las aproximaciones anteriores, y procede de modo hermenéutico con el compromiso de exponer la verdad filosófica pertinente, está haciendo filosofía por sí mismo, aunque junto al autor original. Del mismo modo, cuando en el proceso de esclarecimiento del significado de una película, se clarifican, amplían, o matizan aspectos de la obra de arte de un modo que ésta se enriquezca sin desviarse de la intención filosófica del autor, el exegeta está produciendo filosofía por sí mismo." (Carroll 2011: 263)

A través de la película Serene Velocity, ha mostrado un ejemplo de filosofía construida a través de la imagen en movimiento donde se realiza un análisis 
conceptual que pretende mostrar que el movimiento es una condición necesaria del cine. Ha sostenido que, además de poder encontrar en las imágenes en movimiento una forma de hacer filosofía, la interpretación de estas imágenes es también un ejercicio filosófico, en el sentido de que son contribuciones originales al corpus de conocimiento filosófico. Sin embargo, se posiciona finalmente de parte del escéptico en este punto y aclara que, aunque crea que pueda hacerse filosofía mediante obras de arte realizadas con imágenes en movimiento, piensa que estos casos son escasos y que la mayor parte de lo que se considera filosofía en cine no es sino la ilustración de propuestas filosóficas preexistentes. También aclara que no es el cine experimental el único que considera, pero que la vanguardia modernista constituye a su parecer un lugar natural donde esto puede darse.

En definitiva, Carroll hace un análisis que pretende dar respuestas a quienes se muestren escépticos con la posibilidad de que las "imágenes en movimiento" sean un vehículo filosófico, en el sentido estricto de ser capaces de hacer filosofía. A él le interesa un tipo de película, de imagen en movimiento, que sea capaz de crear filosofía en su desarrollo. Para Carroll pasa a un segundo plano las obras que se limiten a ilustrar filosofía ya existente. Lo que busca son obras en las cuales se desarrolle una filosofía a través de la técnica cinematográfica y, como ejemplo de una película que lo consigue, propone el caso de Serene Velocity. El estudio que hace Carroll acerca de las imágenes en movimiento resulta muy ilustrador con respecto a su capacidad para desarrollar filosofía. Sin embargo, me parece que podemos explorar otras de las cualidades que podemos encontrar en las series de televisión que nos permiten confiar en que las imágenes en movimiento pueden adquirir otro tipo de valor filosófico, o al menos que merecen ser analizadas por la filosofía. Es cierto que, como dice Carroll, no todas las imágenes en movimiento proponen una filosofía original que sea articulada mediante la técnica cinematográfica, pero no por ello me parecen estas más importantes que los casos en los que se plasman filosofías ya existentes o incluso aquellas que incentivan la interpretación y reflexión acerca de sus tramas. A continuación, veremos que las series de televisión tienen mucho que ver con el relato literario y, tras ello, pasaré a explicar en qué sentido entiendo que pueden ser filosóficas. Veremos que se trata de un producto cultural especialmente capaz de ilustrar a los espectadores a través de representaciones sobre las diferentes perspectivas con las que se enfoca una problemática. El espectador en ellas no es pasivo, sino que conoce y experimenta otros puntos de vista y se sitúa ante ellos. 


\section{LAS SERIES Y EL RELATO LITERARIO}

A través de Carroll hemos visto una manera muy estricta de entender la forma en que las imágenes en movimiento pueden ser un vehículo filosófico. Sin embargo, propongo que veamos en ellas la oportunidad de hacer al espectador ampliar su punto de vista. Pero antes, lo que trato de mostrar es que existe un tipo de series de televisión que consiguen sobrepasar la categoría de cultura de masas y recuperan el ideal de paideia al que se asociaba la cultura en su origen. Se trata de un tipo de producción cultural que, a pesar de surgir de la industria y haber sido creadas como un entretenimiento, adquieren la forma de cultura de élites. Su contenido logra convertirse en un producto de excelencia artística porque son capaces de, como decía Adorno, reflejar la realidad social. En este sentido, no podemos decir que en las series de televisión encontremos una cultura rebajada o diluida, puesto que muchas son capaces incentivar la reflexión acerca de nuestros condicionamientos y a cerca del mundo que nos rodea. A través de Adorno veíamos la relevancia que tenía la cultura de masas para la constitución de los individuos y las sociedades, se trataba de una técnica que, en su opinión, no estaba desarrollando su potencial hacia la emancipación. Si es cierto que la cultura ejerce un efecto en la estructura psíquica de sus consumidores, podemos pensar que, en tanto que las series de televisión toman como contenido temas propios de la filosofía y adquieren un formato similar al de la literatura, el efecto que tendrá sobre los espectadores será positivo, emancipador o, incluso, de ilustración. En las series podemos encontrar un valioso medio de difusión, un ejemplo de esto lo podemos ver en las recientes discusiones y debates que ha abierto fuera del mundo académico la serie Westworld (HBO: 2016-actualidad) en relación al transhumanismo y la inteligencia artificial.

Obviamente, no podemos decir esto de todas las series que encontramos en la pequeña pantalla, pero sería un error no atender al éxito cada vez mayor de series que tocan temas controvertidos y que sobrepasan las expectativas del contenido que esperamos encontrar en ellas. Es cierto que, como decía Carroll, es difícil encontrar obras audiovisuales que desarrollen una filosofía original, sin embargo, no por ello debemos dejar de apreciar su capacidad para incentivar la reflexión acerca de temas filosóficos. Encontramos series que muestran desarrollos científicos y tecnológicos, pero también relatan otro tipo de historias, algunas se centran en mostrar diferentes perspectivas y formas de entender la moral, la política, el género e incluso plasmar a través de sus episodios complejos conceptos filosóficos, como el tiempo, lo cual es importante para conseguir representar más dimensiones de las que la apariencia ordinaria nos ofrece. Pero antes de profundizar en lo que quiero 
decir cuando digo que las series pueden ser filosóficas, propongo que veamos la gran similitud que existe entre las series de televisión y los relatos literarios. Las series de televisión aparecen como un producto que presenta no sólo un formato audiovisual propio del cine, sino la calidad artística de la literatura y la complejidad de contenido de la filosofía. Si tenemos esto en cuenta, puede incluso parecernos que el tratarse de un producto más de la industria no tiene por qué ser del todo un inconveniente. Es precisamente por esto por lo que se pueden desplegar los medios necesarios para la producción de series complejas tanto en su contenido conceptual como en su presentación audiovisual.

Las series de televisión pueden ser definidas como producto que se divide en entregas periódicas, o lo que es lo mismo, capítulos, que mantienen entre ellas cierta continuidad argumental o temática consiguiendo convertirse en un tipo de narración propicia para el desarrollo de relatos artísticamente expresivos y con un contenido reflexivo. Al igual que las novelas por entregas de Dickens, Trollope o George Elliot, las series de televisión generan suspense a lo largo de la obra. Brett Martin (Martin 2014) nos dice que, aunque siempre se haya relacionado las series de televisión con el cine, podemos encontrar en ellas algo similar a las novelas por entregas: "la televisión se ha comparado de manera reflexiva con el cine, pero esta forma de narración continuada y sin final estaba, por utilizar una comparación habitual, más próxima a las novelas victorianas por entregas, otra explosión de alta cultura en un medio popular vulgar.”(Martin 2014: 20) Las novelas victorianas por entregas se vieron favorecidas por la novedosa forma de crear, producir, distribuir y consumir las historias así como por la creciente alfabetización, el abaratamiento de la impresión y el surgimiento de una clase consumidora. Podemos decir que ha sido el avance tecnológico en comunicación lo que, en este caso, ha favorecido el surgimiento de este nuevo género de ficción audiovisual que, a ojos de B. Martin, han cambiado la forma en que entendemos la televisión y su contenido:

Resultaron ser especialmente adecuadas no sólo para satisfacer las exigencias comerciales, sino también para hacer frente a los grandes temas de un imperio decadente: violencia, sexualidad, adicción, familia y clase social. (...) Igual que los escritores victorianos, los guionistas televisivos recurrieron a la ironía de criticar una sociedad abrumada por el consumismo industrial, utilizando precisamente el invento más industrializado y consumista de dicha sociedad. (Martin 2014: 21-22)

Para mostrar el paralelismo entre las series de televisión y la literatura, recurriré brevemente al pensamiento de Michel Foucault, que puede hacernos ver qué elementos se encuentran o deben encontrarse en todo relato: 
En toda obra con forma de relato (rècit) hay que distinguir entre fábula y ficción. Fábula es lo que se cuenta (episodios, personajes, funciones que ejercen en el relato, acontecimientos). Ficción, el régimen del relato, o mejor dicho, los diversos regímenes según los que es relatado (recitè): postura del narrador respecto de lo que cuenta (según como forme parte de la aventura, o la contemple como un espectador ligeramente retirado, o quede al margen y la sorprenda desde el exterior), presencia o ausencia de una mirada neutra que recorre las cosas y las gentes asegurando su descripción objetiva; compromiso de todo el relato con la perspectiva de un personaje o de varios sucesivamente; discurso que repite los acontecimientos cuando ya han sucedido. (Foucault 2010: 255)

Para todo aquel que haya visto una serie de televisión, el paralelismo es obvio y, confiando en que se entienda mejor, analizaremos estos elementos a través del caso de la serie Girls (HBO: 2012-2017). Se trata de una serie escrita, dirigida y protagonizada por Lena Dunham, licenciada en escritura creativa por la universidad de Oberlin. En ella encontramos todas las características que componían la fábula: episodios, personajes, funciones y acontecimientos, todo ello narrado con la peculiar capacidad de desarrollar con profundidad la personalidad de cada personaje y el contenido de los hechos. También la ficción, los regímenes del relato, están presentes en una serie de televisión de múltiples maneras: encontramos narradores en primera persona o en tercera, a veces sus protagonistas se apartan para que su historia sea contada por otro o para observar los acontecimientos de otro personaje, en ocasiones se recurre al pasado o se repiten acontecimientos para que podamos entenderlos e incluso se entremezclan las diferentes perspectivas de sus protagonistas. Así, podemos decir que esta serie, al igual que muchas otras, cumplen con características de índole literaria. Al igual que la literatura, una serie de televisión puede pensar lo impensado y, además, las series comienzan a adquirir la capacidad de mostrar lo no mostrado y, para profundizar esta idea, seguiremos analizando apenas un poco más la serie Girls. Su protagonista, Hannah, tiene un trastorno obsesivo compulsivo que, en ocasiones, le hace perder el control y llevar al extremo su carácter. Hannah es un personaje cambiante, imprudente, alocada y, sobre todo, políticamente incorrecta. Su subjetividad se muestra en cada episodio y su cuerpo, criticado por no encajar con los estereotipos de belleza femeninos, es enseñado sin pudor. En esta serie podemos ver cómo se rompe además con diferentes estereotipos femeninos que, aunque comienzan encasillados, van cambiando a lo largo de la trama. Hannah muestra una personalidad diferente y una moralidad que en la realidad puede ser repelida, cuestionada y condenada por la sociedad pero que, en el ámbito de la 
ficción televisiva ha sido aceptada y querida por sus espectadores. Como nos dice Brett Martin, a partir de esta edad dorada de la televisión, se generan personajes "a los cuales, en su día, la opinión pública norteamericana nunca habría permitido instalarse en su sala de estar: infelices, moralmente cuestionables, complicados, profundamente humanos" (Martin 2014: 18).

En este punto me pregunto ¿No serán las series televisivas una forma de mostrar subjetividades, puntos de vista o realidades alternativas? No todas las series ni todo el contenido audiovisual que encontramos en estos medios nos hacen preguntarnos acerca de nuestros condicionamientos, pero sí que encontramos algunas series que permiten llegar al espectador ciertas ideas con las que en ocasiones no está relacionado. A través de este aspecto podemos entender su carácter subversivo: una serie de televisión es capaz de mostrar no solo un lenguaje que traspase los límites de lo que es normalmente expresado en el vocabulario, sino, además, es capaz de hacer ver, de mostrar imágenes, que nunca antes fueron mostradas. Son capaces de acercar temas peligrosos para el poder y cuestionar, por ejemplo, el funcionamiento de la política, como de hecho hacen series como House of cards (Netflix: 2013-2018), o mostrar la forma en que funciona una institución presidiaria y el problema ético que surge al ver lo que supone el exacerbado control de los presos, como ocurre en $\mathrm{Oz}$ (HBO: 1997-2003) o The wire (HBO: 2002-2008). También parece pertinente mencionar la capacidad de transmitir problemas bioéticos, como el caso de la serie Black mirror (Netflix: 2011-actualidad), que reflexiona en un escenario distópico sobre los problemas éticos que surgen del desarrollo de ciertas tecnologías o Electric Dreams (Prime Video, 2017) que recupera directamente un relato literario por tratarse de una serie basada en la novela de Philip K. Dick.

Definitivamente, los guiones han adquirido un valor casi literario y la complejidad de sus tramas es cada vez mayor. Para autores como Foucault la filosofía a partir del s. XVIII podía verse concretada en otros ámbitos, como era la literatura. Quizás hoy podríamos decir que muchos puntos de vista filosóficos son mostrados y desarrollados en las series de televisión. No podemos afirmar que las series vayan a suponer un cambio radicalmente original con respecto al desarrollo filosófico, ni mucho menos que pueda ser un sustituto de la escritura filosófica, tal y como apuntaba Carroll. Sin embargo, llegados a este punto sí que podemos pensar que las series de televisión han supuesto un cambio paradigmático con respecto al desarrollo de la ficción y, desde este punto de vista, sí que podríamos afirmar que suponen un medio capaz de transmitir y problematizar cuestiones filosóficas. 


\section{¿QuÉ DECIMOS CUANDO DECIMOS QUE LAS SERIES SON “FILOSÓFICAS”?}

Hasta ahora hemos visto que las series de televisión, al igual que otros productos de la cultura de masas, pueden ser expresivas y que para autores como Carroll el valor filosófico de las imágenes en movimiento recae en la posibilidad de desarrollar en ellas una filosofía original. Sin embargo, esto muy pocas veces ocurre y podríamos pensar que Carroll tiene una visión un tanto estrecha a la hora de entender la forma en que puede decirse de algo que tenga valor filosófico. Además de las imágenes en movimiento que desarrollan una filosofía original, existen otras que se convierten en relatos que reflejan conceptos o problemas filosóficos en sus tramas y que consiguen incentivar en el espectador una forma de reflexión filosófica. A diferencia de Carroll, considero que podemos decir que las series son filosóficas en tanto que permiten la transmisión y la divulgación de contenido filosófico. Muchas tramas están articuladas casi como experimentos mentales que parecen haber sido diseñadas para que los espectadores alcancen ciertas conclusiones. No debemos presuponer que la formación de los espectadores sea insuficiente para que este tipo de reflexión carezca de valor, a pesar de que no se trate de una reflexión que de lugar al desarrollo de una filosofía original. Por otra parte, otra forma de hablar de las series como filosóficas tiene que ver con el análisis que puede realizarse desde la filosofía para comprender cómo las series plasman puntos de vista que hacen que los espectadores incorporen perspectivas que son ajenas, así como experiencias y conocimiento de situaciones que no han experimentado directamente. Esta idea puede entenderse mejor si nos acercamos al perspectivismo ${ }^{3}$.

Ortega y Gasset es uno de los filósofos que mantiene una posición perspectivista. Entiende que el mundo no es ni espiritual ni material, sino un conjunto de perspectivas. A su parecer todo conocimiento lo es desde un punto de vista determinado. Esto significa que uno adopta un punto de vista que, a la vez, excluye otros: "de la infinidad de los elementos que integran la realidad, el individuo, aparato receptor, deja pasar un cierto número de ellos, cuya forma y contenido coinciden con las mayas de su retícula sensible" (Ortega y Gasset 1970: 103). Lo que dice Ortega nos hace pensar que desde un determinado punto de vista algo puede ser relevantes mientras que, para otra persona, lo mismo puede pasar desapercibido. Si aceptamos esta idea y entendemos que el acceso

\footnotetext{
3 Para más información sobre la filosofía de los puntos de vista, puede consultarse Liz (2013), Colomina-Almiñana (2018) y Vázquez y Liz (2015).
} 
a la realidad se hace desde una perspectiva particular, podemos comprender las series de televisión como una forma de ampliar nuestro acceso a ella. Manuel Liz (Liz, 2013) afirma que la filosofía es reflexión sobre el mundo y nuestra relación con él, pero también reflexión sobre la ciencia y sobre lo que nos hace humanos. Series actuales como El colapso (Movistar+: 2019), Master of sex (Showtime: 20132016) o The Knick (Cinemax: 2014-2015) versan sobre esto. Ofrecen al espectador la oportunidad de reflexionar sobre distintos temas, como, por ejemplo, cuál es el futuro del planeta Tierra, qué nos constituye como humanos o cómo podemos entender el desarrollo de ciertas tecnologías. Las series nos permiten compartir un punto de vista al ponernos en la ubicación o emplazamiento de otras personas. Pero, además, son un medio especialmente capaz de acerquemos a situaciones, roles o realidades con las que no estamos familiarizados. Esto constituye un ejercicio filosófico porque se permite al público comprender formas de pensar, actuar o entender la realidad que sobrepasan la perspectiva del rol que ocupa.

Así, podemos entender las series como un espacio de perspectivas que nos permiten ampliar nuestro punto de vista y adquirir conocimiento. En su intento por describir lo que puede ser considerado como conocimiento, Russell (Russell 1995) nos habla de un tipo de conocimiento que se adquiere por referencia. Si conozco directamente que algo existe, tenemos un conocimiento directo. Pero no es verdad que para saber que algo determinado existe, deba haber conocido directamente la cosa. Russell nos dice que podemos enunciar un juicio verdadero sin tener un conocimiento directo. Este tipo de conocimiento se adquiere por descripción o referencia: "Conocemos una referencia (o descripción) y sabemos que hay un objeto al cual se aplica exactamente, aunque el objeto mismo no nos sea directamente conocido. En este caso decimos que el conocimiento es un conocimiento por referencia." (Russell 1995: 48). Propongo comparar esta definición del conocimiento por referencia con el tipo de conocimiento que se adquiere a través de la visualización de series de televisión, en tanto que nos permiten incorporar experiencias y conocimiento de situaciones que no hemos vivido directamente. Si únicamente tuviéramos conocimiento directo, nuestra visión de la realidad sería muy estrecha. Podemos saber que existen otras realidades sin tener un conocimiento directo de ellas. Por tanto, podemos entender que las series de televisión se sitúan como un espacio de perspectivas, de puntos de vista, que son capaces de ampliar nuestra representación de la realidad y, con ello, aumentar el conocimiento de los espectadores. Carroll parecía tener en cuenta principalmente las imágenes en movimiento que proponían a través de la técnica cinematográfica una filosofía original. A través de su análisis vimos 
que es posible que esto ocurra, pero que no abundan estos casos. Sin embargo, considero que esta no es la única forma en que podemos entender las series de televisión como vehículos filosóficos o que, al menos, no son los únicos casos que resultan interesantes para la filosofía. Comenzábamos este trabajo señalando las referencias a series, cada vez más frecuentes, por partes de filósofos para explicar o ejemplificar conceptos filosóficos. Esto no ocurre porque en todas las series citadas por filósofos se desarrollen teorías filosóficas originales, sino porque parecen resultar unos relatos especialmente capaces de mostrar puntos de vista y, además, de incentivar la reflexión en el público.

Cuando vemos una serie, temporada tras temporada, vemos el desarrollo de una trama interpretada por personajes que mantienen puntos de vista personales, pero también un punto de vista general que pretende plasmar la serie como relato. Además, encontramos un punto de vista principal, el de la cámara, que nos permite acceder al relato. Podría decirse que, al igual que existen visiones que solo puede tener una persona que se encuentre en un determinado emplazamiento, como por ejemplo en lo alto de una montaña, existen situaciones, vivencias, que no son experimentadas mas que por un pequeño grupo de personas. Estas vivencias o situaciones pueden ser de diferente índole, en ocasiones versarán sobre ciencia y tecnología, y otras muestran realidades sociales, como las del colectivo LGTBI, o las vivencias de las mujeres en los grupos amish, etc. Existen muchos tipos de series, y cada una de ellas enfoca la realidad desde un punto de vista determinado sobre el cual el espectador se sitúa.

Para explicar mejor lo que quiero decir me gustaría que centrásemos la atención en Antidisturbios (Movistar+: 2020), una miniserie española dirigida por Rodrigo Sorogoyen, Isabel Peña y Borja Soler. A través de seis episodios, se relata la historia de una brigada de antidisturbios que lleva a cabo el desalojo de una familia que va a ser desahuciada. Cuando llegan, se encuentran con la resistencia de la familia y de unas 30 personas más que están en contra del desalojo. El líder del grupo, Osorio, solicita refuerzos, pero su petición es denegada y proceden a realizar el desalojo en inferioridad de condiciones. La situación se descontrola cuando un inmigrante senegalés que vivía en el edificio cae desde el balcón y muere. Ante este suceso, un equipo de Asuntos Internos de la Policía se encarga de investigar lo ocurrido. Una de las agentes, Laia Urquijo (interpretada Vicky Luengo) se da cuenta de que esa muerte podría haberse evitado, y comienza a investigar qué ha ocurrido. Durante el transcurso de esta serie, vemos el punto de vista personal de cada uno de los seis antidisturbios implicados en el caso. De hecho, cada episodio lleva el nombre de uno de los personajes de la historia, y con cada uno de ellos vamos avanzando más 
en la trama y en el verdadero motivo que impulsó el desalojo. También vemos el punto de vista de Laia, un personaje que conforma el suyo propio a medida que interroga a los antidisturbios y amplía su información acerca de lo ocurrido.

Con el transcurrir de los episodios nos damos cuenta de que lo que pretenden mostrar los creadores de esta serie no es un problema de violencia policial, sino de corrupción. Cada uno de los antidisturbios tiene una personalidad y unos valores distintos, uno de ellos tiene una personalidad violenta y consume drogas y a otro le vemos acosar a una de sus compañeras. Pero también se plasma el punto de vista de un antidisturbio que está orgulloso de su trabajo porque considera que es su forma de contribuir a la sociedad, y otro de ellos está teniendo problemas psicológicos derivados de la presión a la que le somete su oficio. Es cierto que en la trama de esta serie no encontramos el desarrollo de una teoría filosófica original y, desde el punto de vista de Carroll, no podemos decir que contribuya al desarrollo de la filosofía. De hecho, no sabemos qué querían plasmar exactamente sus creadores, pero sí que podemos intentar dilucidar el tipo de reflexión o interpretación que genera en los espectadores.

El análisis filosófico de las series de televisión que propongo supone fijarnos en la interpretación que hace el espectador, en la forma en que la serie puede ser capaz de ampliar su punto de vista. Aquí se hace relevante una de las anotaciones que hace Carroll al respecto de la interpretación por parte de los espectadores, y es que no se conseguirá una interpretación que sea en sí misma una contribución al conocimiento filosófico. No obstante, no por ello merece menos atención la recepción por parte del público de tramas que, sin ser filosóficas, generan una reflexión y un cambio en su punto de vista. Antidisturbios generó un gran malestar en los sindicatos policiales, que consideraron que la serie mancha su imagen. Consideran que se trata de una serie muy alejada de la realidad y que los integrantes de la Unidad de Intervención Policial no son violentos ni agresivos. Por su parte, la Dirección General de la Policía comentó en la Cadena SER que asesoraron a los directores de esta serie y que no es su cometido meterse en la ficción. Los personajes que han sido creados en esta ficción han generado en los colectivos policiales un profundo rechazo debido a que no se ven reflejados en ellos. Esto es entendible, pero parecen no comprender que lo que ha conseguido la serie es precisamente humanizar al colectivo. Cuando comienza la serie, el espectador no puede evitar estar de parte de la familia a la que van a desahuciar. Nunca antes se había generado en mí un sentimiento de empatía con ese colectivo, del cual sólo conocemos, por lo general, su fase más violenta. Sin embargo, me parece que lo que realmente consigue esta serie es que nos posicionemos en el lugar del 
antidisturbio, imaginarnos la presión que deben sentir e, incluso, entender que ellos no tienen por qué estar de acuerdo con las órdenes que reciben. Además, y pese a las quejas del colectivo, también comprendemos que su trabajo es importante para mantener el orden. La visualización de esta serie no es interesante porque muestre la violencia de los antidisturbios, sino porque hace que por un momento nos pongamos en su lugar. Con ella se nos permite ocupar su rol.

En definitiva, lo que pretendo mostrar es que existen series que, a pesar de no ser filosóficas en el sentido en que entiende Carroll, pueden ser interesantes para ser analizadas desde la filosofía. Muchas de ellas consiguen representar puntos de vista que incentivan la reflexión en los espectadores y que amplían, de una forma u otra, su punto de vista. El orden y la forma que toma la realidad es diferente según nuestro emplazamiento y según nuestro rol, y si las series nos permiten acercarnos a otros lugares, personas e historias, conseguimos que nuestra perspectiva se amplíe. Como si de un experimento mental se tratase, las series nos hacen experimentar situaciones con las que, por lo general, no tenemos ninguna relación. Lo que dice Jacques Rancière (Rancière 2008) acerca de las artes escénicas puede servirnos también para comprender mejor esta forma de adquirir conocimiento por referencia. Rancière considera que el teatro, al igual que el resto de artes escénicas que requieren de un espectador, ha sido redefinido y que el poder que pierde el espectador es retomado y reactivado en la performance, en la inteligencia y en la energía que se reproduce en ella. Es decir, Rancière cree a través de la escenificación se le presenta al espectador lo extraño, lo inusual, en definitiva, un enigma en el que debe encontrar sentido:

"Se le forzará de ese modo a intercambiar la posición del espectador pasivo por la de investigador o experimentador científico que observa los fenómenos e indaga las causas. O bien se le propondrá un dilema ejemplar, semejante a los que se plantean a los hombres involucrados en las decisiones de la acción. Se les obligará así a agudizar su propio sentido de evaluación de razones, de su discusión y de la elección que acaba zanjando." (Rancière 2008: 11-12)

El espectador actúa al observar, seleccionar, comparar e interpretar aquello que ve, "Liga lo que ve con muchas otras cosas que ha visto en otros escenarios, en otros tipos de lugares (...) participa en la performance rehaciéndola a su manera." (Rancière 2008: 19) Aunque no todos los desarrollos que veamos en series de televisión sean filosóficos, muchas de ellas consiguen mostrar diferentes perspectivas de entender la moral, la política, el género y, en definitiva, un sinfín de temas que hacen que el público experimente otros roles e incorpore nuevas experiencias a su punto de vista. 


\section{CONCLUSIONES}

Antes de terminar, recapitulemos brevemente lo que hemos venido diciendo. En primer lugar, hemos visto que las series de televisión pueden ser consideradas arte. A pesar de haber sido creadas por la industria para llegar al mayor número de personas posible, en ellas se puede plasmar un contenido expresivo y personal. Para profundizar más en este tema, hemos visto que, además, tienen mucha similitud con los relatos literarios y que es frecuente encontrar en ellas temas de índole filosófica. Lo que he intentado mostrar en este trabajo es que, aunque no podamos considerar que en las series se generen teorías filosóficas originales, el efecto que tiene puede decirse que es filosófico en tanto que permite que el público amplíe su punto de vista. En muchas ocasiones el contenido al que se acerca no es filosófico, pero las reflexiones que se suscitan si que pueden serlo. En otros trabajos (García 2018) he mostrado que las series de televisión pueden ser entendidas como un medio que permite plasmar puntos de vista filosóficos, como lo hace Black. Mirror al reflexionar sobre la ciencia y la tecnología. En ella podemos encontrar un tipo de divulgación o democratización de la ciencia. Esta capacidad para desarrollar en sus tramas conceptos filosóficos es una de las características mas interesantes que encuentro en las series y que considero productivo analizar. Sin embargo, he pretendido mostrar que el interés filosófico por las series de televisión puede ir un poco más allá.

Encuentro en ellas la capacidad, no solo de plasmar contenido filosófico, sino de generar en el espectador una reflexión filosófica. Esto supone entender que la filosofía puede tener un valor que vaya más allá de la investigación académica y de la generación de conocimiento. He querido señalar que la interpretación de las series de televisión no tienen por qué significar la generación de teorías filosóficas (en el sentido que entiende Carroll). En el momento en que el espectador visualiza una serie, incorpora en su background referencias, experiencias y, en definitiva, una especie de conocimiento por referencia que amplía y enriquece su punto de vista. La serie Xena: la princesa guerrera (Universal Studios: 1995-2001), no introdujo en mí ningún conocimiento filosófico, pero sí que incorporó en mi mente la posibilidad de que existiera una princesa que fuese guerrera, muy alejada del modelo de feminidad que podía encontrarse en las princesas Disney. Esto es lo que me parece importante de este tipo de relatos: consiguen introducir ideas en los espectadores. Estas ideas pueden ser de diferente índole, y no siempre tienen por qué implicar un aprendizaje filosófico para que resulte interesante analizarlo desde la filosofía. En ocasiones las series versan sobre ciencia y tecnología, moral o política, pero otras simplemente nos permiten conocer otras formas de pensar 
o de actuar, o muestran distintos tipos de subjetividad que, en definitiva, permiten que ampliemos nuestro punto de vista. El espectador en ellas no es pasivo, sino que conoce y experimenta otros puntos de vista y se sitúa ante ellos.

Laura García Díaz. Universidad de La Laguna lgarciad@ull.edu.es

\section{BiBLIOGRAFÍA}

Adorno, Th. W. y Eisler, H. (2015): El cine y la música, Madrid: Fundamentos.

Adorno, Th. W. y Horkheimer, H. (2005): Dialéctica de la Ilustración, Madrid: Trotta.

CARROLL, N. (2002): Una filosofia del arte de masas, Madrid: Visor.

CARroll, N. (2011): "Haciendo filosofía mediante la imagen en movimiento: el caso de Serene Velocity", en A. García Varas (ed.), Filosofía de la imagen, Salamanca: Ediciones Universidad de Salamanca, pp. 139-265.

Colomina-AlmiñAnA, J.J. (2018): Formal Approach to the Metaphysics of Perspectives, Heildlberg: Springer.

Foucault, M. (2010): Obras esenciales, Madrid: Magnum.

García, L. (2018): "Puntos de vista científicos en las series de television". Daimon, no. 75, pp. $59-72$.

Liz, M. (ed.) (2013): Puntos de vista. Una investigación filosófica. Barcelona: Laertes.

Macdonald, D. (1963): "A theory of Mass Culture", en B. Rosenberg y D. Manning (eds.), Mass culture. The popular arts in America, Sidney: The free press of Glencoe, pp. 59-73.

MARTIN, B. (2014): Hombres fuera de serie, Barcelona: Ariel.

ORTEGA Y GASSET, J. (1970): El tema de nuestro tiempo, Madrid: El arquero.

Ortega y GaSETT, J. (1999): La deshumanización del arte, Madrid: Austral.

RANCIÈRE, J. (2010): El espectador emancipado, Castellón: Ellago Ensayo.

RodRíGUEZ, R. (2012): La polémica sobre la cultura de masas en el periodo de entreguerras. Una antología crítica, Valencia: Universitat de València.

Russell, B. (1995): Los problemas de la filosofia , Barcelona: Labor.

VÁzQuez, M. y Liz, M. (eds.) (2015): Temporal points of viem, subjective and objective aspects, Heildelberg: Springer. 